\title{
REPRESENTAÇÕES DE ALTERIDADE NA GUERRA: APONTAMENTOS CRÍTICOS À PRIMEIRA GUERRA MUNDIAL EM VIRGINIA WOOLF E THOMAS MANN
}

\author{
Luiz Henrique Coelho ${ }^{1}$
}

\begin{abstract}
Resumo:
Em Montanha mágica, Thomas Mann aponta para as transformações políticas, sociais e culturais, relacionadas ao deflagrar da Primeira Guerra Mundial, como um divisor temporal imposto à narrativa. Em Doutor Fausto, Mann expõe o mesmo ponto de vista, com um rigor crítico mais acentuado em relação à guerra iniciada em 1914, mencionando a oposição entre a euforia do período anterior à guerra e o pesar observado após o conflito. Virginia Woolf trata o tema da Primeira Guerra Mundial nos textos Ao farol e Mrs. Dalloway, a partir de um contexto da experiência dos combates. Em Mrs Dalloway, é perceptível a descrição do trauma, como no exemplo dos bombardeios a Londres. Já em Ao farol, o conflito armado é transposto à ideia da passagem do tempo, exposta, sobretudo, no segundo capítulo do romance, intitulado "O tempo passa". A presente análise busca revelar o aspecto crítico de ambos autores em relação à Primeira Guerra Mundial - evento que transformaria tanto os modos de vida, meios de produção e, certamente, a escrita literária - bem como possíveis aproximações entre seus posicionamentos em relação ao tema.
\end{abstract}

Palavras-Chave: Primeira Guerra Mundial; romance moderno; Virginia Woolf; Thomas Mann.

\begin{abstract}
:
In The magic mountain, Thomas Mann points to the political, social and cultural transformations related to the Great War's deflagration, as a temporal divisor imposed to the narrative. In Doctor Faustus, Thomas Mann exposes the same perspective, with a more accurate critic in relation to the conflict which began in 1914, mentioning the opposition between the time before the war and the one observed after. Virginia Woolf deals with the theme of the Great War in To the Lighthouse and Mrs. Dalloway, from the context of the battle experience. In Mrs. Dalloway, it can be noticed the description of trauma - the bombers of London, for instance. In To the Lighthouse, on the other hand, the armed conflict is transposed to the idea of the passage of time, specially, exposed on the second chapter of the novel, Time Passes. The present analysis aims to reveal the critical aspect of both authors in relation to World War I - an event that would transform the ways of life, means of production and, most certainly, the literary writing - as well as the possible approximations between their standings in relation to the theme.
\end{abstract}

Keywords: First World War; modern novel; Virginia Woolf; Thomas Mann.

1 Doutorando em Estudos Literários na UFMG. 


\section{O TEMPO DA GUERRA}

A Primeira Guerra Mundial exigiu uma nova forma de escrita, já que as antigas acepções sobre o passado já não eram possíveis no mundo do pós-guerra. Tanto os veteranos da guerra quanto os civis que sobreviveram lutavam para encontrar novas ideologias sobre a guerra e a natureza humana após o seu fim. Segundo Nancy Topping Bazin e Jane Hamovit Lauter, no texto "Virginia Woolf's Keen Sensibility to War" (1991) [A aguçada sensibilidade de Virginia Woolf à guerra], a guerra causava horror a Woolf. Em sua ficção, sobretudo nos ensaios Um quarto todo seu (1929) e Três Guinéus (1938), a autora expõe o seu desprezo por aquilo que causa eventuais conflitos bélicos. Seus personagens ampliam a noção da representação individual de vítimas para uma perspectiva de destruição da civilização. O lugar no qual são fundadas suas críticas impele o leitor a aprofundar-se naquilo que molda sua compreensão da guerra e as razões para que esta seja tratada de maneira tão impactante. Para Bazin e Lauter, a sensibilidade da autora está "profundamente enraizada em sua própria experiência com a morte, o seu contato direto com atitudes patriarcais em casa e sua visão de cultura, particularmente arte, como única possibilidade de imortalidade para seres humanos" (BAZIN; LAUTER, 1991, p. 14. Tradução minha). As diversas mortes de entes próximos, como sua mãe, sua meia-irmã (a qual assume o papel de sua mãe), seu pai e seu irmão lhe propiciam a identificação com aqueles que estiveram no campo de batalha - lidando diretamente com a iminência da morte, em 1914, algo que ela, por ser mulher, não vivenciou. Woolf passa a entender quão frágil e preciosa a vida é e a guerra, em oposição, era "um pesadelo que não tinha respeito por aquela fragilidade" (1991, p.15. Tradução minha).

O quarto de Jacob (1922) é o primeiro romance que traz a referência das mortes ocorridas no passado de Woolf. O próprio evento fatal que acomete o personagem que empresta seu nome ao título do texto é "desumanizado" (1991, p. 16) pela introdução do fato pela mídia - uma simples contagem de corpos -, contrastante com o sofrimento da narradora, a mãe de Jacob. Woolf descreve assim o noticiário:

Os navios de guerra lançam seus holofotes sobre o Mar do Norte, mantendo suas seções escrupulosamente separadas. A um sinal dado todas as armas apontam para um alvo que (o mestre-artilheiro conta os segundos, relógio na mão - no sexto ergue o olhar) explode em fragmentos. Com igual indiferença uma dúzia de jovens na flor da idade baixa com rostos calmos às profundezas do mar; e impassivelmente (embora com perfeito domínio da maquinaria) sufocam juntos, sem queixume. Como blocos de soldadinhos de chumbo, o exército cobre o trigal, sobre a colina, cambaleia de leve de um lado para o outro, achata-se na terra; apenas através de binóculos pode-se ver uma ou duas peças ainda movendo-se para cima e para baixo, como lascas de fósforos quebrados. (WOOLF, 2003, p. 168)

Segundo Bazin e Lauter, apenas à distância, Jacob poderia ser considerado um "palito de fósforo quebrado". Para a sua mãe, ele é "precioso demais, frágil demais, sagrado demais para ser sacrificado" (BAZIN, LAUTER, 1991, p. 16). Para Woolf, a guerra deveria ser combatida intelectualmente. Sobre isso, em memória ao seu sobrinho Julian Bell, morto na 
Guerra Civil Espanhola, ela escreve: "No momento em que a força é usada, isso torna-se sem sentido e irreal para mim" (WOOLF apud BAZIN; LAUTER, 1991, p. 16)

O quarto de Jacob focaliza sua narrativa na preservação da vida do homem dentro da esfera pública, diferentemente de outros romances da autora, como A viagem (1915) e Noite e dia (1919), onde o foco está na preservação da mulher dentro do casamento. Todos eles têm em comum o senso de preocupação com o individual. As perdas no âmbito público foram profundamente sentidas por Woolf, devido às suas perdas no âmbito pessoal. A herança intelectual da autora era pacifista, pois seu pai era contrário à guerra e ao militarismo, o qual chegou a proibir os filhos de seguir carreira militar. (WOOLF apud BAZIN; LAUTER, 1991, p. 16-17). Contudo, as referências à guerra são cunhadas muito particularmente por Woolf. A dor sentida por Mrs. Flanders, na morte do filho, revela a sensibilidade da autora para com as mulheres que perdem seus filhos, após anos dedicados em sua criação. Já em Ao farol, a morte da personagem Prue indica a atenção dispensada pela autora ao risco que as mulheres correm na hora do parto.

Em Mrs. Dalloway (1925), Woolf cria uma eloquente condenação ao militarismo, à guerra e, também, um monumento em memória da Primeira Guerra Mundial, ao evocar a morte nas batalhas. No romance, a atmosfera pesada da guerra ainda paira sobre Londres reforçando a presença do trauma de sua vivência para a autora e seus conhecidos. A devastação inesperada continua viva para seus parentes e amigos. Página após página, o pesar esmagador é revisitado, como no exemplo do sobrevoo de um avião por sobre a cidade, que causa tensão entre seus habitantes, ao lembrarem dos bombardeios à cidade. Cada elemento da cultura do pós-guerra é lembrado ou trazido ao centro do texto e os locais e rituais reais de luto são tratados com uma veneração direta, apartados de sátira e hostilidade, como se Woolf também estivesse reconhecendo o que adquire-se com a morte.

Para Bazin e Lauter, Woolf se identifica mais diretamente com as vítimas da guerra. Descreve o sofrimento mental, comum aos veteranos do conflito, metaforizado na condição de Septimus Smith, a qual se assemelha à sua própria, conseguinte às perdas da mãe e à meia-irmã. Ambos se sentem muito "pequenos" (BAZIN; LAUTER, 1991, p. 17)

A experiência de guerra está evidenciada não apenas no sofrimento dos personagens centrais de Mrs. Dalloway, mas, também, nos secundário, a partir de suas memórias e reflexões. Na narrativa, encontram-se momentos de contemplação silenciosa, que se remetem a uma reverência aos mortos, como na passagem:

Pois era em meados de junho. A guerra havia acabado, exceto para alguém como Mrs. Foxcroft, na embaixada, a noite passada, aflita porque aquele belo rapaz havia sido morto e agora o antigo solar acabaria nas mãos de um primo; ou Lady Bexborough, que inaugurou um bazar beneficente, disseram, com o telegrama na mão: John, seu predileto, morto; mas havia terminado; graças a Deus - acabada. (WOOLF, 2011, p.12)

Tais reflexões expõem a face pormenorizada da escrita de Woolf. Para além da descrição de um certo macrocosmo londrino atingido pela guerra e que ainda lida com as suas consequências, a autora observa algumas minúcias latentes ao comportamento dos perso- 
nagens, as quais se remetem aos distúrbios provocados pelo evento. O fim da guerra, ao mesmo tempo, não significa que esses distúrbios estejam superados. Por exemplo, pode-se citar o momento em que Richard Dalloway corre à casa, com flores para Clarissa, sua esposa, pensando "na guerra, e milhares de pobres chapas, com toda a vida pregressa, amontoados juntos, metade já esquecidos." (WOOLF, 2014, loc. 17080, e-book. Tradução minha) Virginia Woolf problematiza a representação da guerra inicialmente em "Modern fiction" (1921), ao narrar "pequenos milagres diários" denominados como "halos - auréolas - luminosos de vida" (WOOLF, 2015, e-book, p.65), se referindo, por exemplo, à grande revelação sobre a qual Lily Briscoe fala em Ao farol (1927) e que talvez nunca aconteça. Em Ao farol, Woolf toma a desorientação e desespero da década seguinte ao conflito e os transformam em um "encontro inesperado às cegas". Ela se remonta à guerra de uma maneira nova, poética e comovente. Inclui o conflito de forma modesta e deliberada, na narrativa; as referências a ele, portanto, podem passar facilmente despercebidas. No capítulo "A janela", Woolf oferece pistas sutis da destruição por vir e reduz a guerra a uma brincadeira de criança. Os horrores e consequências seguintes são articulados a partir da superação de Woolf às limitações da linguagem ao narrá-los. Os personagens atestam o vínculo de Woolf com uma escrita que apresenta formalmente características percebidas nas primeiras décadas do século XX e aliviam sua frustração acerca do passado criando algo novo. Em "A janela", os filhos da senhora Ramsay desaparecem da mesa de jantar e ela lamenta as divisões, diferenças de opiniões e os preconceitos arraigados em seus filhos. Tais características são muito próximas daquelas que provocam um conflito armado. Ela deseja que seus filhos permaneçam contentes e inocentes como eram antes, algo que não voltaria a acontecer.

No capítulo o "O tempo passa" as metáforas sobre a guerra emergem na passagem das estações e, sobretudo, nos momentos das tempestades. Na terceira parte do capítulo, Woolf se pergunta:

Mas o que é, afinal, uma noite? Um curto espaço, especialmente quando a escuridão diminui tão cedo, e tão cedo um pássaro chilreia, um galo canta ou um verde desmaiado se aviva, como uma folha revirada no oco de uma onda. A noite, entretanto, sucede à noite. O inverno guarda uma boa safra delas em estoque e distribui igualmente, imparcialmente, com dedos infatigáveis. Elas aumentam; elas escurecem. Algumas delas mantêm no alto planetas límpidos, placas de luminosidade. As árvores outonais, devastadas como estão, trajam o clarão de bandeiras esfarrapadas ardendo na escuridão dos frios porões de catedrais onde letras douradas e páginas de mármore descrevem a morte na batalha e contam como, muito longe, os ossos desbotam-se e queimam nas areias indianas. As árvores outonais cintilam à luz amarela do luar, à luz das luas de colheita, a luz que suaviza a energia do trabalho, e amacia o restolho, e traz a onda batendo toda azul na praia. (WOOLF, 2013, p. 17, e-book)

Mesmo diante de passagens que apontam para a atenção dispensada pela autora à Primeira Guerra Mundial, existem análises que apontam para as diversas modificações sofridas pelo capítulo mencionado acima. James Haule, no seu texto "To the Lighthouse and the 
great war: The Evidence of Virginia Woolf's Revisions of 'Time passes'” [ Ao farol e a grande guerra. A evidência das revisões de Virginia Woolf do “Tempo passa”], (1991), cita o trecho de uma carta enviada a LLewelyn Davies, em 23 de janeiro de 1916, na qual Woolf define a eventualidade de uma guerra como uma "ficção masculina (a guerra)" que "segue, mais um dia - sem que alguma jovem e vigorosa mulher, nos empurrando, e a atravesse marchando. Você vê algum senso nisso?[...]". Para Woolf, a guerra não era e não seria escrita a partir do ponto de vista das mulheres. Nesse sentido, segundo ela, como mulher, ela não tinha país. "Como mulher, eu não quero um país. Como mulher, meu país é o mundo inteiro" (WOOLF apud HAULE, 1991, p. 164-165. Tradução minha). Para Woolf

Ninguém que seja consciente de suas próprias impressões, desde 4 de agosto de 1914, pode acreditar que a história, como ela é escrita, assemelha-se minimamente da história como ela é vivida; mas como somos, para a maioria, quiescentes e, se céticos de nós mesmos, satisfeitos por acreditar que o resto da humanidade acredita, que não temos o direito de reclamar se estamos excluídos mais uma vez das histórias dos historiadores (WOOLF, 2014, loc. 110687, e-book. Tradução minha)

As críticas ao comportamento patriarcal, para além dos comentários até aqui mencionados, tornam-se mais potentes em Ao farol, corporificadas na personagem de Mr. Ramsay. Suas atitudes revelam sua crença de superioridade em relação às mulheres, implicando a necessidade de que ele as proteja de forma heroica. Para Bazin e Lauter, o seu sucesso, em vida, depende disso. (BAZIN; LAUTER, 1991, p. 19) Ao elevar tal heroísmo presente na vida doméstica de Mr. Ramsay, Woolf o relaciona com o heroísmo masculino em defesa da nação, associando-o, também, às linhas recitadas pelo personagem de "The charge of the light brigade", do autor Alfred Tennyson. No entanto, tal heroísmo, presente na relação do personagem com Mrs. Ramsay e os filhos, concretiza-se, não por atos heroicos, mas, sim, por sua posse da verdade. O descontrole emocional do personagem, como lembram Bazin e Lauter, é percebido quando ele aceita o risco de não cumprir com esta noção de verdade, ao arriscar-se especulando sobre a derrota de tropas inglesas em Balaclava. Nesse ponto, ele passa a afrontar a esposa e, angustiado, também o faz com a pintora Lily Briscoe. Esta forma de usar a violência, ao ser imputada ao imaginário de guerra, liga diretamente as relações políticas públicas e domésticas inseridas no patriarcado. (1991, p. 19)

Entretanto, Woolf desvia das análises sociais ou políticas, no romance, atendo-se a uma análise psicológica da sua própria conexão com a guerra e o trauma. Ela posiciona a morte da mãe - sob a perspectiva da sua família - junto à brutalidade de uma guerra, e suas incontáveis perdas - sob a perspectiva de uma nação. A diferença de temperamento entre a primeira parte e a terceira parte de Ao farol é muito relevante. Na segunda parte, que as separa, ocorre a morte de uma mãe, conforme os padrões vitorianos que ela representa - e a guerra mundial que mata o seu filho. (1991, p. 19). Ademais, a segunda parte descreve a ruína da casa de verão dos Ramsay, arruinada por intempéries climáticas e pela ação do tempo, mas o que, figurativamente destrói a casa é a guerra, conforme a passagem 
Mas por mais que ela dormitasse e dormisse, chegaram, no fim do verão, sons agourentos, como as batidas marcadas de martelos amortecidas pelo feltro, que com seus repetidos choques afrouxaram ainda mais o xale e rachavam as xícaras de chá. De quando em quando, algum cálice retinia numa cristaleira como se uma voz gigante tivesse gritado tão alto na sua agonia que os copos que estavam numa outra cristaleira também vibravam. Então, o silêncio caía novamente; e, então, noite após noite, e às vezes em pleno meio-dia, quando as rosas brilhavam e a luz voltava sua forma sobre a parede, tinha-se a clara impressão de que nesse silêncio e nessa indiferença e claridade caía o surdo ruído de alguma coisa que tombava, (WOOLF, 2013, e-book)

\section{O ÚLTIMO CARNAVAL ANTES DE 1914}

Thomas Mann, em suas cartas entre 1914 e 1923, afirma que, pela distância do seu nascimento ao último tratado de paz assinado pela Alemanha, guerras não faziam parte de suas experiências pessoais. Na correspondência, contudo, o autor sugere que o início da Primeira Guerra Mundial dificulta a condução da vida como anteriormente. Nas palavras do autor: "[...] devo dizer que me sinto abalado e envergonhado com a forte pressão da realidade. Até hoje, estava otimista e descrente [...]" (MANN, 2004, p. 37 apud CALDAS, 2014, p. 109). O autor, que, até 1918, se posicionava de forma conservadora em relação aos governos alemães - e também em relação à sua população -, se mostra insatisfeito com o seu país natal ainda no começo da guerra. O evento desperta sua sensibilidade histórica (CALDAS, 2014, p. 109) e, diante de uma pergunta feita em uma entrevista ao jornal Berliner Tageblatt sobre quais livros deveriam ser lidos naquele momento, ele responde

Tempos como este exercem sobre o espírito e a alma os efeitos mais contraditórios. Eles os melhoram, enlevam, purificam, mas também lhes causam danos. [...] Tudo que não se relacione imediatamente com o cotidiano selvagem, agitado, grandioso, e, nem fale dele, parecerá abstrato, distante, ultrapassado, vindo de outro mundo (MANN, 2002, p. 52 apud CALDAS, 2014, p. 110)

O contraste entre a vida pregressa de Mann e o sentimento iniciado pela guerra, em 1914, é percebido ainda nas primeiras páginas do romance A Montanha mágica (1924), intituladas "Propósito" (2006), as quais demonstram o sentimento do autor em relação à passagem do tempo, simbolizada, também, pela crise da República de Weimar, posterior à guerra, e como teria dificuldade em ser um narrador - em suas palavras, "este murmurante evocador do passado" (CALDAS, 2012, p. 132). Como anunciado logo em suas primeiras linhas, o objeto do romance é a história de Hans Castorp, cujos "fatos aqui referidos passaram-se há muitos anos já. Estão, por assim dizer, recobertos pela pátina do tempo, e em absoluto não podem ser narrados senão na forma de um remoto passado." (MANN, 2006, p. 13) Nessa referência ao tempo, Mann sugere dois tempos para a narrativa, o que expõe também sua opinião sobre a Primeira Guerra Mundial. Os fatos contidos na trajetória de 
Castorp se encontram em uma outra época, "nos velhos tempos, naquele mundo de antes da Grande Guerra", que se opõe à cisão provocada pelo conflito armado: "cujo deflagrar [da guerra] marcou o começo de tantas coisas que ainda mal deixaram de começar" (MANN, 2006 , p. 14). No seu romance posterior, Doutor Fausto, de 1947, com uma posição mais objetivamente contrária à participação alemã em ambos os conflitos bélicos - a Primeira e a Segunda Guerras Mundiais - Mann trata a oposição entre um momento de euforia com as novidades técnicas presentes na virada do século XIX para o XX e a transformação dessa euforia em pesar, a partir de 1914. No romance, Mann descreve tal oposição do seguinte modo, a partir do personagem Serenus Zeitbloom):

O carnaval de 1914 de Munique deixou-me recordações vivas, ou melhor, fatídicas. Semanas de pândega e confraternização, as faces esquentadas pelas festas entre a Epifania e a Quarta-feira de Cinzas, com sua multidão de festejos públicos ou particulares, dos quais eu (Serenus Zeitblom), o ainda jovem professor do ginásio de Freising, participava, ora sozinho, ora em companhia de Adrian. Era o último Carnaval antes do início daquela guerra de quatro anos, que agora, na nossa visão histórica, funde-se com os horrores dos nossos dias, constituindo uma única época. A assim chamada Primeira Guerra Mundial acabou para sempre com a inocente vida estética da cidade sobre o Isar, e se me permitem me expressar assim: com seu conforto dionisíaco. Pois esse era também o período em que, sob os meus olhos, na nossa roda de conhecidos se produziram certos desenvolvimentos de destinos individuais, que, obviamente, permaneciam quase despercebidos do resto do mundo, mas tinham de acarretar catástrofes, das quais deverei falar nestas páginas, porquanto tocavam de perto a vida e a sorte de meu herói, Adrian Leverkühn, e também porque ele esteve envolvido numa delas, como sei no meu íntimo, de um modo misterioso e fatal." (MANN, 2015, loc. 6230, e-book)

Essa oposição corresponde, também, ao momento da ruptura modernista, já que a Primeira Guerra influenciou as propostas formais de diversos autores daquele período. A exemplo disso, podemos exemplificar com a representação fragmentada do personagem do demônio, no Doutor Fausto. Enquanto o Mefistófeles goethiano é representado por apenas uma figura, no romance de Mann ele surge em diversos pontos da narrativa e, em cada um deles, é representado por uma nova figura.

É necessário mencionar outra opinião de Thomas Mann - correspondente aos anos anteriores ao seu exílio nos EUA - em relação à Primeira Guerra Mundial, antagônica àquela expressa em ambos os romances. A guerra, para o autor alemão,"possuía um caráter purificador". O trabalho do artista seria comparável ao do soldado. Em comum eles teriam "[...] o desprezo pelo que, na vida burguesa, se chama 'segurança' - o conceito favorito do burguês - e o hábito de conduzir a vida perigosamente, de maneira arriscada, concentrada [...] sem piedade por si mesmo, radicalismo moral, dedicação máxima”. Para Mann, a palavra não poderia se limitar a uma mimetização da realidade e, por isso, a forma não poderia funcionar como um "espelho refletido", mas deveria ter seu "próprio brilho". É nesse senti- 
do que a palavra se torna política, pois amplifica a realidade, expondo a sua transitoriedade, em suas formas e aparências. A purificação seria, portanto, uma elaboração refinada da forma. O rigor em relação à escrita talvez seja o sentido "da maneira como Thomas Mann interpretou positivamente a guerra, isto é, como possibilidade dos alemães entrarem em uma nova fase de sua formação política e de declarar superada a era prussiana."

Em 1916, Mann teria dito a Phillip Wittkop (Professor de literatura em Freiburg, considerado especialista em literatura de guerra) que não somente desconhecia romances sobre a guerra, como não tinha qualquer interesse pelo gênero. (MANN, 2002, p. 29-30 apud CALDAS, 2014, p. 110-111)

\section{CONCLUSÃO}

Virginia Woolf e Thomas Mann inauguram uma nova forma de narrativa em seus romances. Nela, estaria intrinsecamente contida a vivência de ambos na Primeira Guerra Mundial. No entanto, nos textos de Virginia Woolf o conflito é apresentado a partir de comentários ou metáforas que evocam-na de modo que ela pareça estar gravado na vida dos personagens. Um exemplo encontra-se na passagem com Lady Bexborough, na qual o impacto da morte do filho se dissolve em meio à totalidade da cena. Já em Thomas Mann, as menções à guerra são bem pontuadas, como um momento à parte na narrativa, onde, ora se apresenta o tom do romance - como na divisão anunciada em Montanha Mágica -, ora surge como a memória do narrador, em uma reflexão acerca dos tempos passados, como em Doutor Fausto.

Certamente, o que une os autores é a forma modernista, fragmentada, marcada pelo fluxo de consciência e por uma relação muito pessoal com os conflitos bélicos. A crítica a esses conflitos, em ambos, é abordada em meio a narrativas que percorrem inúmeras alternativas para o tema da guerra. Se em Woolf a guerra surge como uma reafirmação dos lugares de homens e mulheres na sociedade e perpassa sua experiência pessoal com a morte, em Thomas Mann a guerra torna-se uma metáfora para uma sociedade adoentada, contaminada por um nacionalismo exacerbado. Ambos se ligam por uma perspectiva da passagem do tempo como elemento que configura, diretamente, em descrições claras, uma noção de ruína, como um prenúncio de uma nova época para a humanidade. 


\section{REFERÊNCIAS BIBLIOGRÁFICAS}

BEUTIN, Wolfgang et al. „Die deutsche Literatur des Exils“. In: Deutsche Literaturgeschichte: Von den Anfängen bis zur Gegenwart. Stuttgart: J.B. Metzler, 2001, p. 451-459.

CALDAS, Pedro Spínola Pereira. "A educação estética de Hans Castorp: A montanha mágica como Bildungsroman" In: Viso - Cadernos de estética aplicada Revista eletrônica de estética. Rio de Janeiro, 2012, p. 128-150. Disponível em: http://revistaviso.com.br/pdf/Viso_12_PedroCaldas.pdf Acesso em: 20 jun 2018 13:45:12.

CALDAS, Pedro Spínola Pereira. "O murmurante evocador do passado: A montanha mágica e o romance de formação após a Primeira Guerra Mundial”. In: História da historiografia: international journal of theory and history of historiografy. Ouro Preto, 2014, p. 107-120. Disponível em: file:///home/chronos/u-d2e1f2cf65f9c9c03f359b3cd1c22325dcc67c56/Downloads/Montanha\%20 m\%C3\%A1gica\%20e\%20a\%201\%20guerra\%20mundial.pdf Acesso em: 20 jun 2018 14:34:45.

MANN, Thomas. A Montanha mágica. Trad. Herbert Caro. Rio de Janeiro: Nova Fronteira, 2006.

MANN, Thomas. Doktor Faustus. Frankfurt am Main: Fischer Taschenbuch Verlag, 2013.

MANN, Thomas. Doutor Fausto. São Paulo: Companhia das Letras, 2015. E-book.

WOOLF, Virginia. Ao farol. Belo Horizonte: Autêntica, 2013.

WOOLF, Virginia. “Essays”. In: Virginia Woolf. The Complete Works. E-art, 2014. E-book.

WOOLF, Virginia. "Ficção moderna". In: O valor do riso e outros ensaios. São Paulo: Cosac Naify, 2015. E-book.

WOOLF, Virginia. Mrs. Dalloway. Rio de Janeiro: Saraiva, 2011.

WOOLF, Virginia. O tempo passa. Trad. Tomaz Tadeu. Belo Horizonte: Autêntica, 2013. E-book.

WOOLF, Virginia. Jacob's room. In: Virginia Woolf. The Complete Works. E-art, 2014. E-book.

WOOLF, Virginia. O quarto de Jacob. Trad. Lya Luft. Rio de Janeiro: Nova Fronteira, 2003. 
